\title{
Sensorless Control of DC Microgrid Based on Artificial Intelligence
}

Akpolat, Alper Nabi; Habibi, Mohammad Reza; Dursun, Erkan; Kuzucuoglu, Ahmet Emin; Yang, Yongheng; Dragicevic, Tomislav; Blaabjerg, Frede

\author{
Published in: \\ IEEE Transactions on Energy Conversion
}

Link to article, DOI:

10.1109/TEC.2020.3044270

Publication date:

2021

Document Version

Peer reviewed version

Link back to DTU Orbit

Citation (APA):

Akpolat, A. N., Habibi, M. R., Dursun, E., Kuzucuoglu, A. E., Yang, Y., Dragicevic, T., \& Blaabjerg, F. (2021). Sensorless Control of DC Microgrid Based on Artificial Intelligence. IEEE Transactions on Energy Conversion, 36(3), 2319-2329. https://doi.org/10.1109/TEC.2020.3044270

\section{General rights}

Copyright and moral rights for the publications made accessible in the public portal are retained by the authors and/or other copyright owners and it is a condition of accessing publications that users recognise and abide by the legal requirements associated with these rights.

- Users may download and print one copy of any publication from the public portal for the purpose of private study or research.

- You may not further distribute the material or use it for any profit-making activity or commercial gain

- You may freely distribute the URL identifying the publication in the public portal 


\title{
Sensorless Control of DC Microgrid Based on Artificial Intelligence
}

\author{
Alper Nabi Akpolat, Student Member, IEEE, Mohammed Reza Habibi, Student Member, IEEE, Erkan \\ Dursun, Member, IEEE, Ahmet Emin Kuzucuoğlu, Member, IEEE, Yongheng Yang, Senior Member, \\ IEEE, Tomislav Dragičević, Senior Member, IEEE, and Frede Blaabjerg, Fellow, IEEE
}

\begin{abstract}
Nowadays, DC microgrids are preferred in the field of renewable energy. The autonomous DC microgrids aim to provide smooth power flow from renewables to loads. While satisfying certain load profiles and sustaining the power as the desired level, the control of power converters is considerable. To ascend the resilience of DC microgrids, battery storage systems (BSSs) are also used as a backup unit for supplying uninterrupted power. The main task of BSSs is to compensate for the lack of power when the load is higher than supplied power or store the surplus of power in case that the load demand is less than the extracted power. In other words, by draining and storing the power, BSSs help to increase the flexibility of the system and keep the main DC bus voltage within acceptable bounds. This study introduces artificial intelligence (AI)-based method to diminish the number of implemented sensors and control power converters without reducing efficiency. In this paper, artificial neural networks (ANNs) as a subset of AI are exploited. Diminishing the number of sensors in the control layer makes the system more reliable. To validate the effectiveness of the proposed system, offline and online time-domain simulations are performed in MATLAB/Simulink.
\end{abstract}

Index Terms--DC Microgrids, artificial intelligence (AI), power electronic converters, sensorless control application, battery storage system (BSS).

\section{INTRODUCTION}

M icrogrids can be described as a part of power grid with distributed energy resources (DERs) based on renewable energy resources (RESs), power electronics converters, energy storage systems, and loads, which can operate either standalone or interact with the utility grid [1]. DERs are expected to generate a smooth power, but it is not completely possible due to their intermittent nature. Because of this unbalanced nature, they are not adopted to operate without any converter that has a sort of control algorithms to extract maximum power efficiently. Thereby, the power electronics converters have a crucial duty in dispatching desired power [2]. In this context, the optimum operation of DERs which are the main source of microgrids is critical for uninterrupted energy transfer. Control and power management strategies of DERs affect power quality, stability, and robust performance [3], [4]. The DC microgrids have advantages when comparing to conventional AC microgrids in terms of improving efficiency, reducing the cost of electrical infrastructure [5]. Thus, a multipurpose trend has been existing to convert microgrids from $\mathrm{AC}$ to $\mathrm{DC}$ due to certain encountered challenges such as skin effect, frequency synchronization, and reactive power control. The main benefit of a DC microgrid is that the system can perform easily with DC types of DERs [6]. So, encountered problems in a DC microgrid can be coped with easier than an AC microgrid [7].

For the sustainability, an integration of a battery storage system (BSS) may afford a flexible and dynamic energy management system to increase stability, which can be controlled with optimization techniques in DC microgrids. On the other hand, high penetration of renewables in the power system is considered to be more pretty common in the near future; thus, batteries can play a vital role in the reliable and cost-efficient grid-integration of intermittent energy sources. In other words, BSSs are indispensable units of microgrids. In microgrids, the BSS acts as a complementary source to store surplus energy and shed back to the loads when the need arises [8]-[10]. Related to literature, different kinds of traditional or modern control schemes have been implemented to improve the performance of the power converters in DC microgrids. Most of the non-linear control schemes (e.g. PI, deadbeat, multi-loop feedback, LQG, model reference adaptive, sliding mode, and hysteresis voltage control, etc.) contain some disadvantages like high switching frequencies which makes the system weaken for adequate control of the power electronic converters and result in resonance issues [11]. Conventional control approaches depending on the detailed parameters of the system model may encounter various problems in a sudden load change and in case of failure. Furthermore, non-model based approaches such as model predictive, neural networks, and fuzzy logic, which do not require a system model to overcome this situation, have been preferred in the field of power electronics recently and it has been observed to give satisfying results [12], [13].

Except for the conventional approaches, the key idea here is to handle the operation of a designed DC microgrid explicitly with artificial intelligence (AI)-aided control. AI-based smart systems intend to cope with them by developing algorithms for specific problems that cannot be solved. AI tries to mimic the mindset in the human brain, which is difficult to understand for building smart infrastructures of complicated problems [14]. Since AI does not require any information or mathematical

This work was supported in part by Marmara University-BAPKO with FEN-C-DRP-150218-0063 project number and YÖK-YUDAB scholarship commission. (Corresponding author: Alper Nabi Akpolat.)

A. N. Akpolat, E. Dursun, and A. E. Kuzucuoğlu are with the Department of Electrical-Electronics Engineering, Faculty of Technology, Marmara University, Istanbul, 34722, Turkey (e-mails: alper.nabi@ marmara.edu.tr, erkandursun@ marmara.edu.tr, and kuzucuoglu@ marmara.edu.tr).

M.R. Habibi, Y. Yang, and F. Blaabjerg are with the Department of Energy Technology, Aalborg University, Aalborg East, 9220, Denmark (e-mails: mre@et.aau.dk, yoy@et.aau.dk, and fbl@et.aau.dk).

T. Dragičević is with the Department of Electrical Engineering, Center of Electric Power and Energy, Technical University of Denmark, 2800 Kongens Lyngby, Denmark (e-mail: tomdr@elektro.dtu.dk). 
model of the system in which will be applied and also not have any computational burden, thereby it can be assumed as a blackbox system. AI applications in power electronics have been discussed with three aspects namely, design, control, and maintenance [15]. AI-aided systems accord effectively for power electronics-based systems in terms of easy and economical practicality [16]. Recent issues such as metaheuristic methods for control or optimization problems, lifetime estimations, system identifications, condition monitoring, and fault detection systems, reliability, etc. have mostly been mentioned in recent years [17]-[20].

To come around various issues in DC microgrids with the help of AI methods, in this work, we elucidate the application and usage of artificial neural networks (ANNs) which is a subset of AI methods to reveal the desired practicality. As well as applicability, the sustainable control of the power converters is the heart of the DC microgrids, which is vital to the system operation. The measurement sensors in the control layer will adversely affect the system if an error or failure occurs due to being vulnerable. This was our first motivation for which vulnerable sensor will be eliminated.

Since the DC microgrids suffer from the constant and pulsed load demands, the authors in [21] propose that neural network, fuzzy, reinforcement learning, etc. based-advanced control strategies for power electronic converters to alleviate the requirements of rapid response, high robustness, and large stability tolerance versus the load demand. In [22], a sensorless control method has been preferred to predict the grid voltage at remote points that cannot be sense. In particular, various sensorless control applications as ANN-based data-driven methodologies are often used for controlling power electronics and motor drives [23]. In recent years, estimator-based control has been considerable interest in wind energy conversion and motor drive systems for sensorless control by predicting the torque, flux, and speed instead of individual machine variables [24]-[26]. Similarly, the authors in [27] discuss virtual fluxbased voltage and current reconstruction technique by estimating three-phase voltages and currents of a microgrid enabled with a proposed sensorless droop control strategy to improve reliability and cost-effective solution. In [28], the authors offer to implement AI-based intelligent control strategies for power converters of a hybrid energy generation system. The authors in [29] argue that the feedforward PI speed controller based on AI can estimate the speed accurately for a DC motor. To tackle with uncertainties and parameter variations in a permanent magnet synchronous machine, an ANN-based observer is performed to estimate the position, torque, and speed data in [30], [31]. To assure stability, reliability, and power quality, establishing smart systems based on AI techniques can be preferred. This approach may decrease the power uncertainty, and also make the system more robust [32]. Another effective approach [33] to operate virtual plants with decentralized estimation has been implemented through a special kind of recurrent neural networks (RNNs) named long short term memory (LSTM).

To cover mentioned themes, the focus of this paper here is to address a robust sensorless control strategy of the DC microgrid to satisfy the load side in a cost-effective and highreliable way by applying a feedforward neural network which is able to model static nonlinear relationship unlike RNNs. Before proceeding, it is important to note that the applying neural network is divided into two main phases regarding offline and online parts. At first, the offline mode is performed to collect enough data for training neural networks that will be a predictor. After training in offline mode, neural networks are well-tuned and ready to estimate the relevant variables. This approach proposes to prepare a well-trained and tuned network with the help of a large amount of input data in the training phase. After that, the network aims to estimate the required inputs of power converters' controller without using sensor measurements to reduce the number of voltage and current sensors. The results show that the proposed sensorless control strategy can afford to perform in variable circumstances. Briefly, the main contribution of this study can be summarized as follows:

1) Estimating the DC microgrid parameters used for the control layer enables to implement effective sensorless control and developing a self-contained design to increase reliability with fewer sensors data without any communication delay.

2) A comparison between measured and estimated values of the system to demonstrate the effectiveness of the proposed application for the DC microgrids under changing input (meteorological data) and output (constant loads) is provided.

3) The proposed method satisfies the loads with a rapid response, fewer oscillations, and large reliability tolerance through well-trained ANNs with high accuracy at every moment, which affects the system positively is beneficial.

The remainder of this paper is organized as follows. Section II elucidates the physical structure of the DC microgrid. Section III explains the control of a standalone DC microgrid. Proposed application is elaborated in Section IV. Section V evaluates the results and discussion of the proposed method. Finally, conclusion and future work remarks are given in Section VI.

\section{PhysicAl Structure OF DC Microgrid}

The DC microgrid contains a photovoltaic (PV) array and a wind turbine system (WTS) with its permanent magnet synchronous generator (PMSG) as DERs, a battery bank as BSS, power electronic converters, filters, and AC loads. Fig. 1 depicts the DC microgrid system is discussed. While the PV array and wind turbine (WT) system are the main power source, the BSS is designed as a complementary power source.

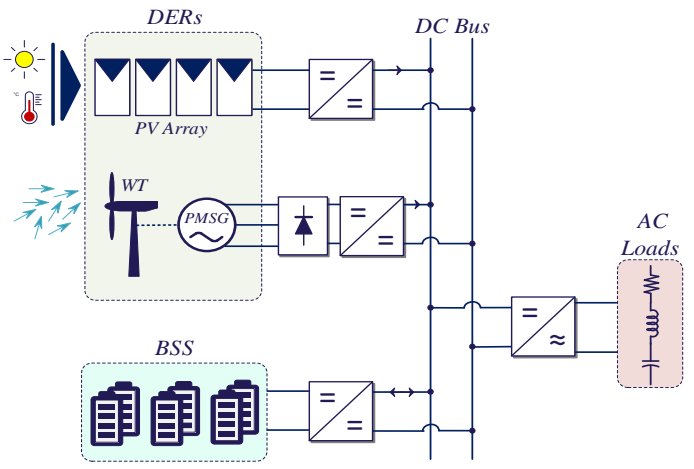

Fig. 1. General description of a DC microgrid. 
The PV array is rated to $1 \mathrm{~kW}$ and is specified by a single diode model. A maximum power point tracking (MPPT) control takes maximum power from the solar panel using a unidirectional DC-DC boost converter. In terms of temperature and solar irradiance, the voltage and current of PV panels have been varying accordingly the power as well. The power of the $\mathrm{PV}$ panel $P_{P V}$ is expressed as

$$
P_{P V}=V_{P V} \cdot \mathrm{I}_{P V},
$$

where, $V_{P V}$ and $I_{P V}$ are the voltage and current of the PV panel. Typically, an MPPT algorithm is operated in the converter control adjusting reference PV voltage- $V_{\text {ref }}$ in order to enhance the energy yield as much as possible in any condition. In addition, the MPPT algorithm is operated with a PI control that generates a duty cycle to begin PWM by sensing the difference between a reference voltage (e.g., produced from the MPPT) and instant $\mathrm{PV}$ voltage- $V_{P V}$. In this way, maximum power from $\mathrm{PV}$ arrays to DC bus is provided easily. Perturb and observe ( $\mathrm{P} \& \mathrm{O})$ method is one of the most preferred MPPT algorithms was selected to examine the change in power in the voltagepower characteristic.

The WTS consists of a WT with PMSG, a rectifier, and lastly converter. The WT also boosts its power to the DC bus with a full bridge diode rectifier and unidirectional DC-DC boost converter. The wind energy conversion system has been designed as four parts. The WT of this system has a vertical axis turbine of three blades with a fixed pitch angle $\left(\beta=0^{\circ}\right)$. The turbine has coupled with a three-phase PMSG to generate an $\mathrm{AC}$ power and then deliver the power to the $\mathrm{DC}$ bus with a full bridge diode rectifier and DC-DC boost converter. The turbine output power can be seen that it is equal to $320 \mathrm{~W}$ for 0.8 per unit of nominal mechanical power, so the nominal output power corresponds to $400 \mathrm{~W}$ at base wind speed (i.e., $12.5 \mathrm{~m} / \mathrm{s}$ ). The output power and mechanical torque of the wind energy conversion system can be expressed as

$$
P_{m}=c_{p}(\lambda, \beta) \frac{\rho A}{2} v_{\text {wind }}^{3},
$$

where, $P_{m}$ is mechanical output power of the turbine (W), $c_{p}$ is the performance coefficient of the turbine is dependent on $\lambda$ and $\beta, \rho$ is air density $\left(\mathrm{kg} / \mathrm{m}^{3}\right), A$ is the turbine swept area $\left(\mathrm{m}^{2}\right), V_{\text {wind }}$ the wind speed $(\mathrm{m} / \mathrm{s}), \lambda$ is tip speed ratio of the rotor blade tip speed to wind speed, and lastly $\beta$ the blade pitch angle (degree).

As to the main power source, the BSS contains six pieces of batteries, three pieces connected in parallel and two pieces of them in series. To form the aforementioned BSS, the battery bank has been installed on behalf of the energy storage unit comprises of 6 pieces of battery. Each of them has a $200 \mathrm{Ah}$ capacity and their output voltage is $12 \mathrm{~V}$. Consequently, the capacity of the BSS is $600 \mathrm{Ah}$ and its output voltage is $24 \mathrm{~V}$, with $14.4 \mathrm{kWh}$ energy capacity. Besides, a mathematical generic model that we used in this paper, was modeled for fast battery model development based on datasheet values. The handled model belongs to a variable battery voltage $\left(V_{\text {Batt }}\right)$ that can be expressed in both two modes such as discharge and charge for lead-acid battery, corresponds (3) and (4) respectively. The parameters can be adjusted to exemplify a battery type and its discharge characteristics. A typical discharge curve is formed of three parts such as exponential, nominal, and discharge areas. While (3) expresses the function of discharge for a lead-acid battery, (4) does the function of charge.

$$
\begin{gathered}
V_{\text {Baut }}=E_{0}-R_{\text {Buat }} i_{\text {Bat }}-K \frac{Q}{Q-i_{\text {But }} t} i_{\text {But }} t-K \frac{Q}{Q-i_{\text {But }} t} i^{*}+\exp (t), \\
V_{\text {But }}=E_{0}-R_{\text {But }} i_{\text {But }}-K \frac{Q}{Q-i_{\text {But }}} i_{\text {But }} t-K \frac{Q}{i_{\text {But }} t-0.1 Q} i^{*}+\exp (t),
\end{gathered}
$$

where, $E_{0}(\mathrm{~V})$ is battery constant voltage, $R_{\text {Batt }}(\Omega)$ is internal resistance, $i_{\text {Batt }} t$ actual battery charge (Ah), $I_{\text {Batt }}(\mathrm{A})$ is battery discharge current, $K$ is polarization constant ( $\mathrm{V} /(\mathrm{Ah})), Q$ is battery capacity (Ah). Meanwhile, the utility grid is another main power supply. The utility grid can feed the loads while the produced power and state of charge (SoC) level of the battery bank are lower than the point that is not capable of providing power to the loads. A bidirectional inverter with an LCL filter is the key component of the system, which conducts power from the DC bus to the load side. The connection between utility grid and microgrid is controlled by a bidirectional DC-AC inverter. The parameters of the system components belong to the DC microgrid system are given in Table I, in Appendix. We modeled the system to test under changing conditions and validate the control methodology.

\section{CONTROl OF A StANDAlONE DC MiCROGRID}

Since ANN nodes require to be trained with relevant data, we need to operate the system with any controller firstly. The general configuration and control structure of the solar energy conversion system with a boost converter which depicts acquiring the maximum power from the PV array. To reach maximum power point (MPP) calculated by the MPPT algorithm, a cascaded control mechanism drives the converter. That cascaded control mechanism is a series of voltage, current, and pulse width modulation (PWM) controller. For dynamic convergence and maximum accuracy, the step size was chosen for the $\mathrm{P} \& \mathrm{O}$ algorithm as $0.01 \mathrm{~V}$. The uncontrolled full-bridge rectifier utilizes only diodes as switching semiconductor devices in applications, where the control of power flow is not compulsory. Additionally, a DC-DC boost converter is preferred in order to manage the power flow [34]. Then the power is dispatched to the DC bus with a unidirectional DC-DC boost converter existing by a PI reference voltage-current controller. Besides, the BSS feeds the loads permanently with a bidirectional DC-DC buck-boost converter, which is connected directly to the DC bus, even if the lack of generation exists as well. The aim of this converter is to keep the DC bus voltage and battery current on the desired level as much as possible, once the voltage changes depending on production and consumption. This purpose is managed by controlling both the DC bus voltage and the battery current with the help of cascaded-PI control structure. The operation modes of this converter can be described as buck and boost mode. While the buck mode means charging, the boost mode corresponds to discharging of the battery bank. The switching frequency is achieved for power converters as $10 \mathrm{kHz}$. As can be seen in Fig. 2 , it depicts the general control structure for the whole system. 


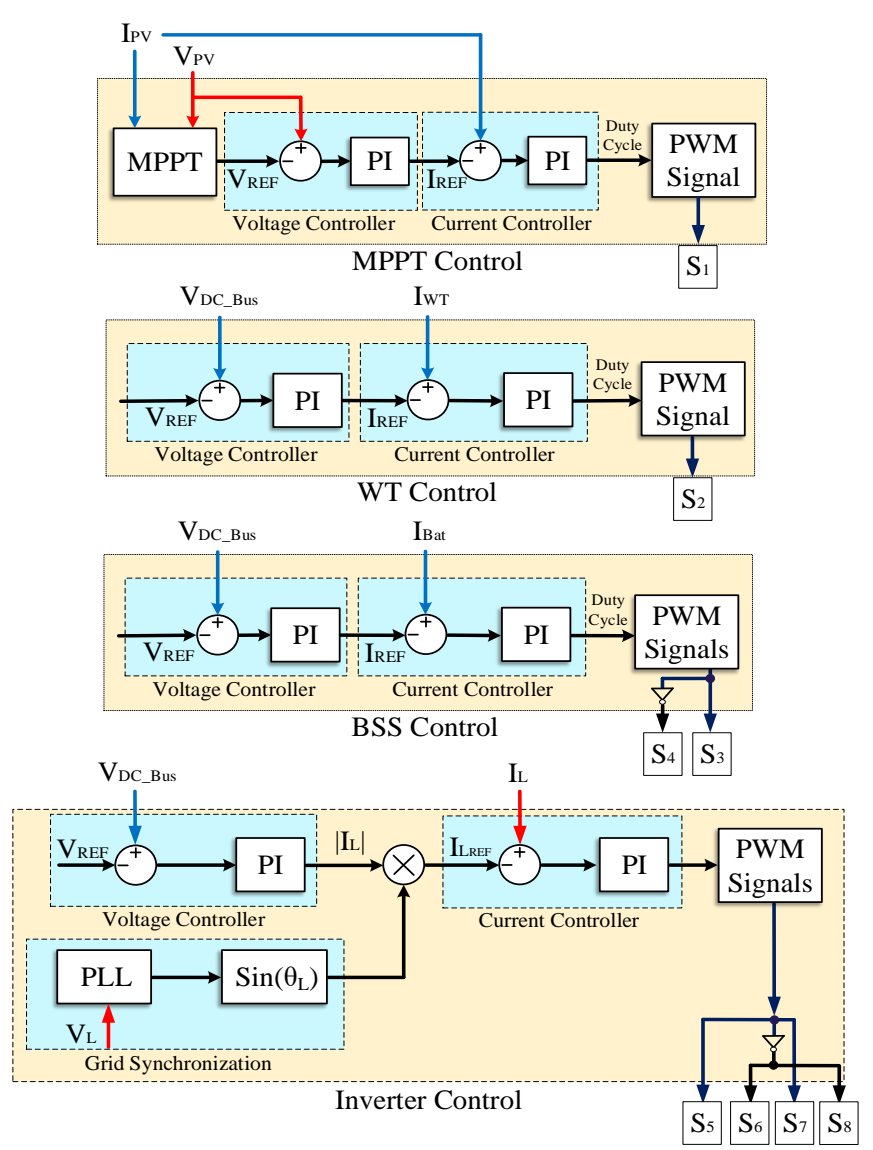

Fig. 2. Control diagram of the local controllers with cascaded-PI for training the system in offline phase.

On the other side, bidirectional DC-AC inverter dispatches the obtained power to the loads adjusting the DC bus voltage and providing the grid synchronization via phase-locked loop (PLL). That controller was used for two goals: i) to supply the required data for the offline training of the ANN, and ii) to contrast and analyze the performance with the proposed ANN controller under constant loads.

\section{Proposed SENSORLeSS ApPliCATION BASED ON ARTIFICIAL NEURAL NETWORKS}

The classical control based on a PI or linear controller is not fully capable of capturing all system dynamics. To this end, ANNs have been used in different applications. For instance, in [35], an ANN-based monitoring system for PV panel was introduced. In addition, in [36], ANNs were implemented to detect cyber-attacks in DC microgrids. Also, an ANN-based model predictive control strategy to control three-phase inverters with an LC filter is proposed by [37] to achieve lower THD and improve the steady and dynamic behavior of the system. Because of the effective performance of ANNs, they can be considered a powerful tool for different purposes such as estimation of different variables in power applications. The goal of this method is to show how ANN can be used properly in DC microgrid to reduce the number of sensors. To control DC microgrids, data related to voltage and current of converters should be gathered and sent to the controller to manage the
DERs. In this study, we aimed to implement one of the basic neural network structure to keep simplicity.

When examining the structure of the feedforward neural network, it is worth mentioning that elements of feedforward neural network are separated layers. The signs from the input layer to the output layer are transmitted by a one-way connection. While being a link from one layer to the next, no link exists in the same layer. In feedforward networks, the outputs of the cells in the layers are the input of the next layer. If the layer by layer network is examined, the input layer transmits the information from the external environment to the cells in the intermediate (hidden) layer without making any changes. The output of the network is calculated by processing it in the hidden layers and the output layer. To sum up, the feedforward network can model static nonlinear relationships (unlike recurrent networks that model dynamic relationships). Since only static relationships are needed, the feedforward networks would be sufficient. Similarly, the feedforward networks can generally respond to problems such as classification, regression, and prediction by applying the delta learning rule. For the input presented to the network, the output of the network is compared with the actual result. Because of these reasons, we adopted a multi-layer feedforward neural network structure which is simple and has less complexity. An ANN estimates data series of $m(t)$, when obtaining past values up to $k$ pieces of $n(t)$ series as

$$
m(t)=f(n(t-1), n(t-2), \ldots, n(t-\mathrm{k}+1), n(t-\mathrm{k})) .
$$

Fig. 3 illustrates the structure of an ANN with $n$ inputs and one output. In the ANN, a neuron plays a critical role and it has one or more input signals and one output signal. The input signals of a neuron can come from the neurons, which are located in the previous layer and the output signal of the neuron can go to the neurons of the next layer. In this work, ANNs with one hidden layer are implemented. Due to the proper results and also because of reducing the complexity, the number of hidden layers did not increase to a number more than one. If the ANN has $n$ inputs, one hidden layer with $m$ neurons, and one output, the output signal of the $i^{\text {th }}(1 \leq i \leq m)$ neurons of the hidden layer can be calculated as

$$
z_{i}=f_{\text {hidden }}\left(\sum_{j=1}^{n}\left(x_{j} \times w_{h, j, i}\right)+b_{h, i}\right),
$$

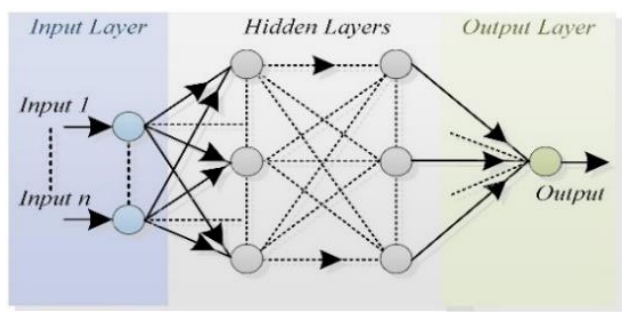

Fig. 3. The general structure of an ANN with $n$ inputs and an output.

where, $w_{h, j, i}$ is the weight factor between the $j^{\text {th }}$ neuron of the input layer and $i^{\text {th }}$ neurons of the hidden layer. Furthermore, $b_{h, i}$ is the bias factor for the $i^{\text {th }}$ neurons of the hidden layer. In addition, $x_{j}$ is the $j^{\text {th }}$ input of the ANN and $z_{i}$ is the output of the $i^{\text {th }}$ neurons of the hidden layer. In (6), $f_{\text {hidden }}($.$) is the activation$ 
factor of the hidden layer. Also, the output of the ANN can be expressed as

$$
y=f_{o}\left(\sum_{j=1}^{m}\left(z_{j} \times w_{o, j}\right)+b_{o}\right) .
$$

In (7), $y$ is the output of the ANN and $w_{o, j}$ is the weight factor between the $j^{\text {th }}$ neuron of the hidden layer and the neuron of the output layer. Also, $b_{0}$ is the bias factor of the neuron in the output layer and $f_{o}($.$) is the activation factor of the output layer.$ To implement the ANN, it is important to train the model with a well-tuned. The goal of the training is to calculate the optimized and proper values of the weight factors and bias factors of the neurons for the ANN. The sets of $W_{h}, W_{o}, B_{h}$, and $B_{o}$ represent the weighting factors between the input layer and the hidden layer, the weighting factors between the hidden layer and the output layer, bias factors of the hidden layer, and bias factor of the output layer of the ANN, respectively. $W_{h}, W_{o}, B_{h}$, and $B_{o}$ are given as

$$
\begin{gathered}
W_{h}=\left\{w_{h, j, i} \mid 1 \leq j \leq n \text { and } 1 \leq i \leq m\right\}, \\
W_{o}=\left\{w_{o, j} \mid 1 \leq j \leq m\right\}, \\
B_{h}=\left\{b_{h, i} \mid 1 \leq i \leq m\right\}, \\
B_{o}=\left\{b_{o}\right\} .
\end{gathered}
$$

To train the ANN, inputs and output data should be gathered. Then, the gathered data can be used to create input and output data sets, and based on which are the optimized values of the $W_{h}, W_{o}, B_{h}$, and $B_{o}$ can be obtained. After the calculation of the weight and bias factors, the well-tuned ANNs can be implemented in the system.

Upon evaluating the trained neural networks, two terms possess high importance as mean squared error (MSE) and correlation coefficient $(R)$. The smaller $M S E$ denotes more accurate predictions. Accordingly, if $R$ converges to 1 , it corresponds that the accuracy of the network is higher. These terms are expressed as

$$
\begin{gathered}
M S E=\sqrt{P(e-d)^{2}}, \\
R=\frac{1}{m} \sum_{r=1}^{m}\left(\frac{e-\mu_{e}}{\sigma_{e}} * \frac{d-\mu_{d}}{\sigma_{d}}\right),
\end{gathered}
$$

where, $P$ is the expected value, $e$ is the predicted value, $d$ is the desired values of the proposed method, and also $\mu_{d}$, and $\sigma_{d}$ are the mean and standard deviation of desired values, respectively.

Primarily, the outputs of the ANNs that have a static relationship with inputs are appointed with the aim of eliminating the data sensing for control layers. Subsequently, pertinent inputs to be selected for outputs are determined. Once the system operates at the training phase, inputs and outputs of the ANNs are gathered to be trained with the help of being measured variables such as relevant meteorological, current, and voltage data. Obtaining satisfactory results from the trained ANNs is related to the selection of proper data with enough sampling time. After getting desirable training results, the determined sensor data are deactivated and the outputs of the ANNs are linked to the controllers at the exploitation phase. Fig. 4 shows the training and also exploitation phases of the
ANNs. It should be noted that the training phase is done offline for the ANNs. For the better extraction of the system's dynamic and having better estimation capability, the historical values of the inputs are considered in Appendix, Table II explains the ANNs features that have been implemented. For a better illustration of the implementation of the ANNs, there will be a substantial number of sensors that are not needed anymore. These eliminated sensors data can be observed in Fig. 5, (i.e. estimated data) which have been estimated through the ANNs. In terms of improving the reliability of the system, requiring fewer sensor data are considerable.
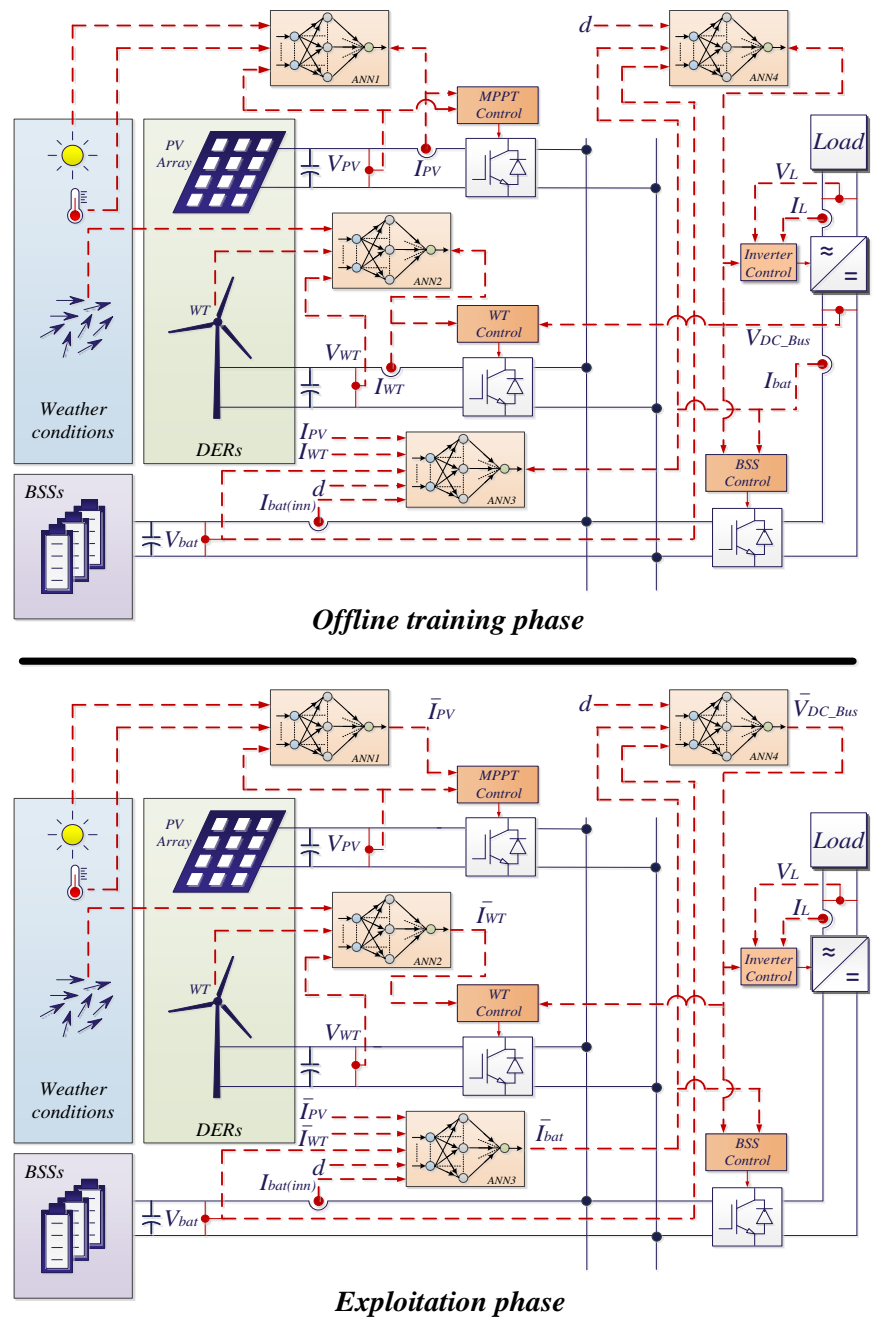

Fig. 4. The offline training and exploitation phases of the ANNs.

Also, Fig. 5 depicts a summary version of Fig. 4 after the offline phase, namely, in the exploitation phase. Table III illustrates the inputs and outputs of ANNs for each power converter. At first, for MPPT control in the DC-DC boost PV converter, the output PV voltage $\left(V_{P V}\right)$, the solar irradiance $(G)$, and temperature $(T)$ data are located as inputs, then the output PV current $\left(I_{P V}\right)$ is estimated. For the WTS, the torque $\left(T_{M}\right)$ applied to the generator shaft, the wind speed $\left(W_{S}\right)$, and the output WT voltage $\left(V_{W T}\right)$ are obtained as inputs. Then the output WT current $\left(I_{W T}\right)$ is estimated in a similar way. The estimated output currents $\left(\bar{I}_{P V}\right.$ and $\left.\bar{I}_{W T}\right)$, the inner battery current $\left(I_{B a t(i n n)}\right)$, the battery bank voltage $\left(V_{B a t}\right)$, and duty cycle $(d)$ of the DCDC buck-boost battery converter are taken into consideration to 
estimate the output current of the battery bank $\left(I_{B a t}\right)$. Lastly, the estimated $\bar{I}_{B a t}$ facilitates for obtaining the DC bus voltage $\left(V_{D C} \_\right.$Bus $)$with $V_{B a t}$ and $d$ inputs for inverter control. Totally, four sensors can be reduced for whole control levels apart from the reduced number of sensors for each controller in Table III.

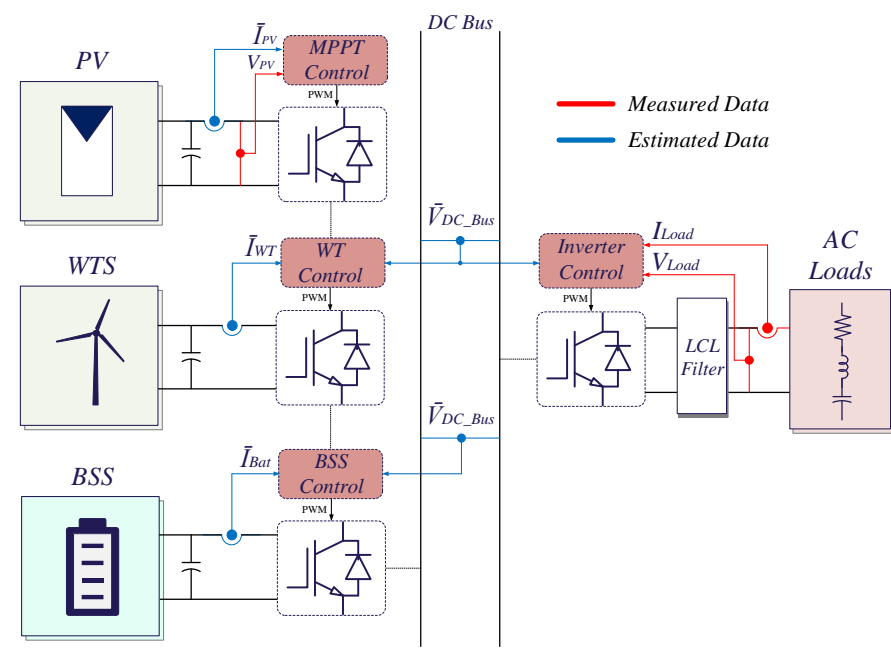

Fig. 5. Summary of the circuit configuration and control structure of the microgrid enabled by proposed sensorless AI-based control strategy.

\section{Simulation RESUlts AND DisCUSSION}

Before proceeding, it is noteworthy to consider that the cascaded-PI reference voltage-current controller has been adopted as a main controller of the system. Similarly, in [38], sudden variations can be controlled effectively using the same cascaded-PI controller for PV-Battery-based applications. As proposed by [39], the evidence we have comprehended the benefit to prefer a cascaded-PI voltage-current controller for a hybrid wind-solar-battery-based microgrid. Further optimal operations of DERs is an effective way of providing the resilient response of the DC microgrids, which are carried out in [40] with implementing cascaded-PI for primary control of BSS. In order to compare our promising results that are obtained through the applied controllers, we found it appropriate to perform cascaded-PI on the system as a robust basis.

As expected, our results prove that the availability of the estimated signals overlaps with the real measured ones. The substantiates of the results support previous findings in the literature such as excellent steady-state performance, fewer harmonics, and dynamic operation. According to simulation results, the findings validate that all loads are fed smoothly. The generated duty cycle of the PV converter is perturbed by a fixed-step. The continuous perturbation results in undesired oscillation in the steady-state operation. Instead of the control signal with undesired oscillation, it is pretty convenient to generate the estimated control signal without oscillation due to the step size of the MPPT. The input profile for PV and WTS depicts the operating conditions, such as the ambient temperature, solar irradiance, and wind speed. These exposed data are varied with meteorological conditions. In Fig. 6, a variable input profile data defined in the simulation have been used to resemble a real profile.

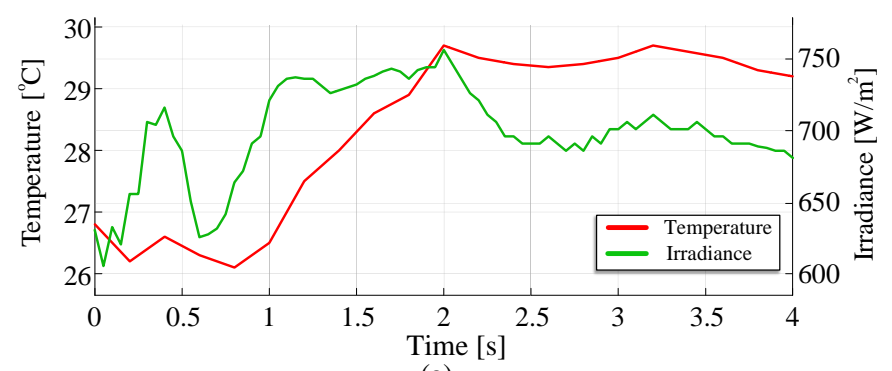

(a)

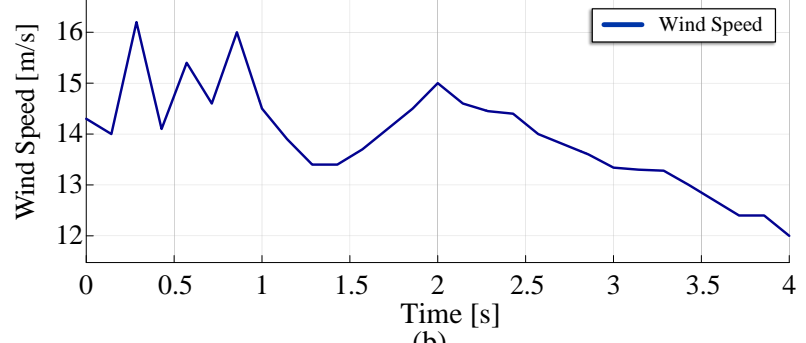

(b)

Fig. 6. Instantenous input profile during simulation period: (a) Temperature and solar irradiance for PV, (b) wind speed for WTS.

As seen in Fig. 7, the real i.e., measured and estimated currents for the MPPT control of the PV array converter are expressed by the measured and estimated values $\left(I_{P V}\right.$ and $\left.\bar{I}_{P V}\right)$. Similarly, the measured and estimated values of the WT current $\left(I_{W T}\right.$ and $\left.\bar{I}_{W T}\right)$ can be shown in Fig. 8.

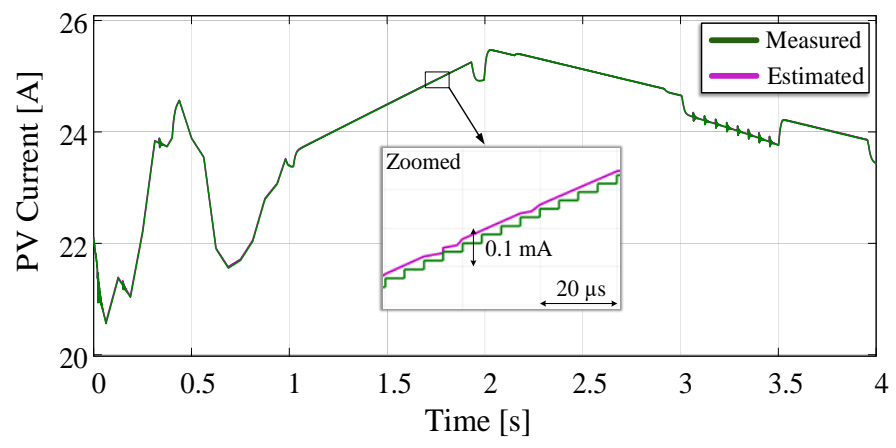

Fig. 7. Measured and estimated currents for the MPPT control of PV array.

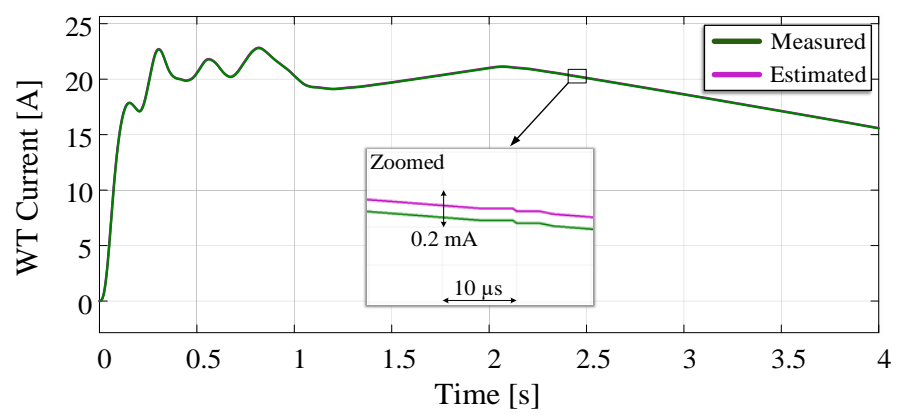

Fig. 8. Measured and estimated currents for the WTS control.

As shown in Fig. 9, the measured and estimated values of the BSS currents $\left(I_{B a t}\right.$ and $\left.\bar{I}_{B a t}\right)$ are displayed. Fig. 10 elucidates the measured and estimated DC bus voltages $\left(V_{D C_{-} B u s}\right.$ and $\left.\bar{V}_{D C_{-} B u s}\right)$ that we have in the system likewise. The rated powers and feeding times of the AC loads are given in Table I. It can be observed by injecting the current in Fig. 9 and also decreasing the voltage in Fig. 10, as compared with the powers of the loads. 
For a different event, the status of the instantaneous power dispatch can be seen by switching Load IV ON and OFF when Load III is activated. $I_{B a t}$ and $V_{D C_{-} B u s}$, which constitute one of the main variables of power to the inverter through the DC bus, respond to load changes faster with the proposed method.

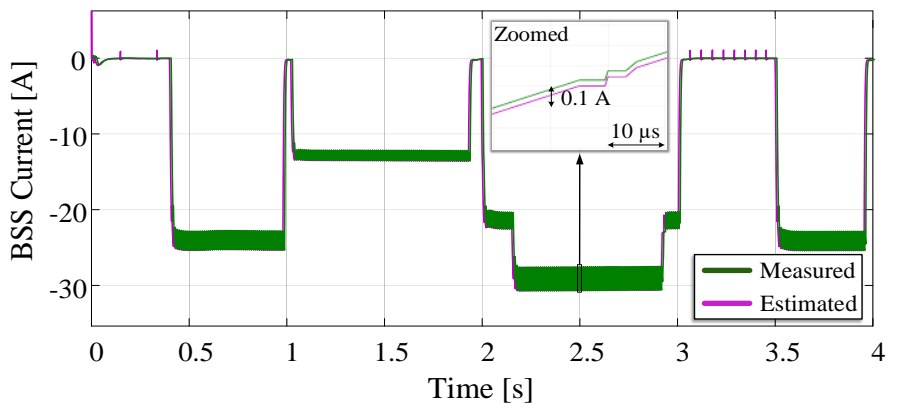

Fig. 9. Measured and estimated currents for BSS control.

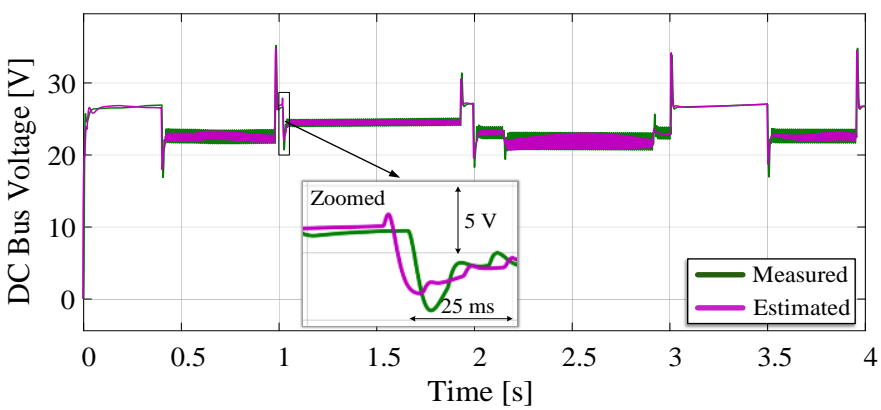

Fig. 10. Measured and estimated voltages for BSS and inverter control.

Without applying the proposed method, the impact of communication delay of the sensors is approximately $10 \mathrm{~ms}$, which can be seen in Figs. 11 and 12. On the other hand, the steady-state oscillation difference between the measured and estimated data exists, and the oscillation in the proposed method is less. In other words, as can be noticed, the peak to peak amplitude of oscillations in steady-state operation (i.e., while the load is $\mathrm{ON}$ ) regarding the estimated current proves superior performance more than the measured one because of being fewer.
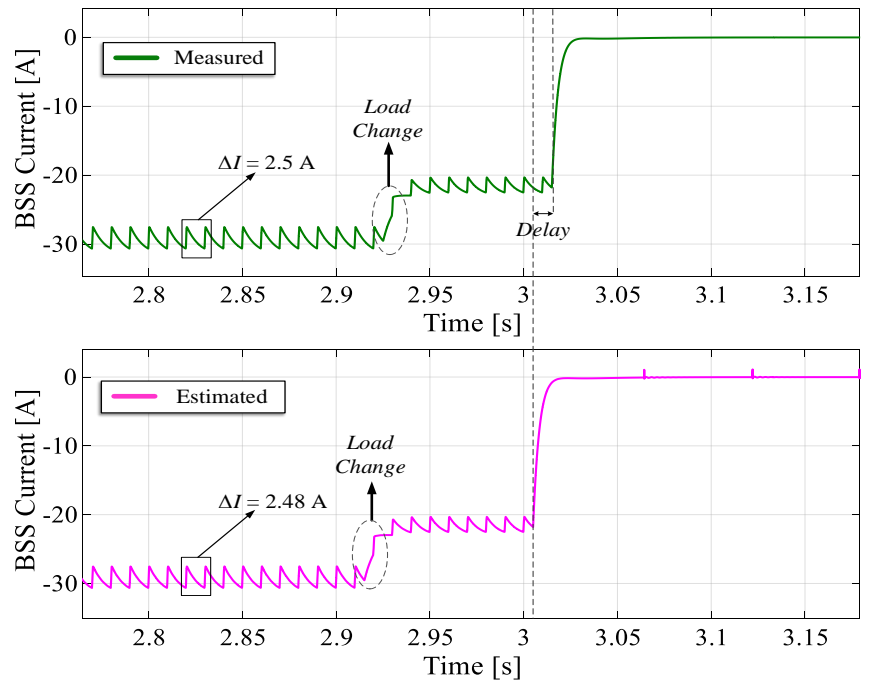

Fig. 11. Impact of communication delay among measured and estimated currents for BSS control under load change.
Similarly, Fig. 12 presents the impact of communication delay between the measured and estimated DC bus voltage on the relevant controller under load change. Also, compared between both methods, it is explicit that the steady-state oscillation is superior in the proposed method.
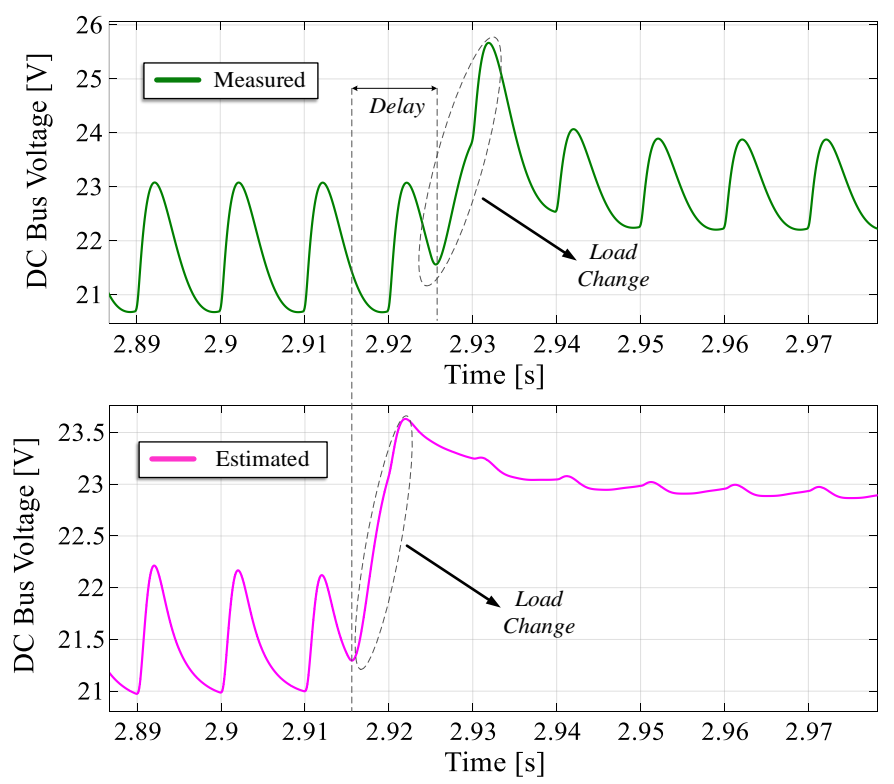

Fig. 12. Impact of communication delay among measured and estimated DC bus voltages for BSS and inverter control under load change.

A comparison of measured (i.e., existing PI-controller) and estimated (i.e., ANN-based controller) values is shown in Fig. 13 in some load change time intervals. As seen in Fig. 13(a) $\bar{V}_{D C_{-} B u s}$ shows superior performance compared to $V_{D C_{-} B u s}$ regarding overshoot, oscillation, and slew rate. Moreover, another comparison between measured and estimated BSS currents is also indicated in Fig. 13(b) under responses of load change. For another load change time interval, a comparison of measured and estimated values can be seen in Fig. 14, additionally. As can be observed in Figs. 13 and 14 the robustness of estimated signals can be distinguished evidently.

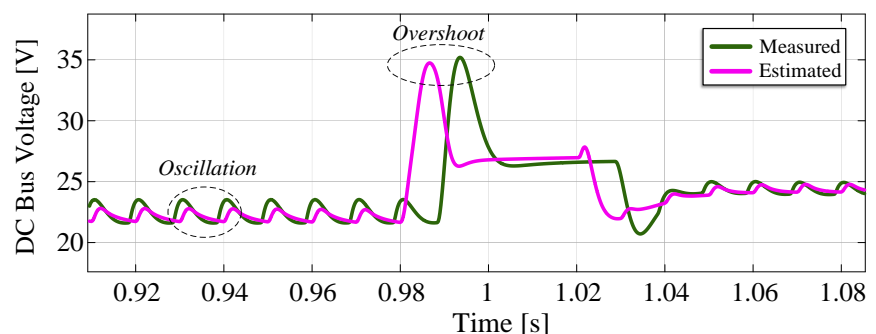

(a)

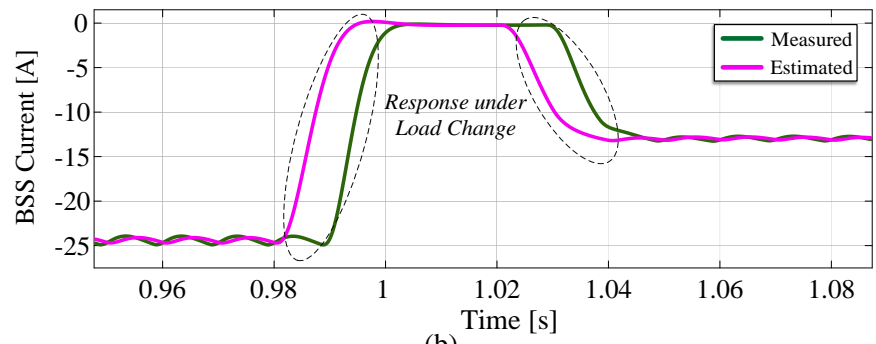

(b)

Fig. 13. Comparison of measured and estimated (a) DC bus voltages and (b) BSS currents under load change. 


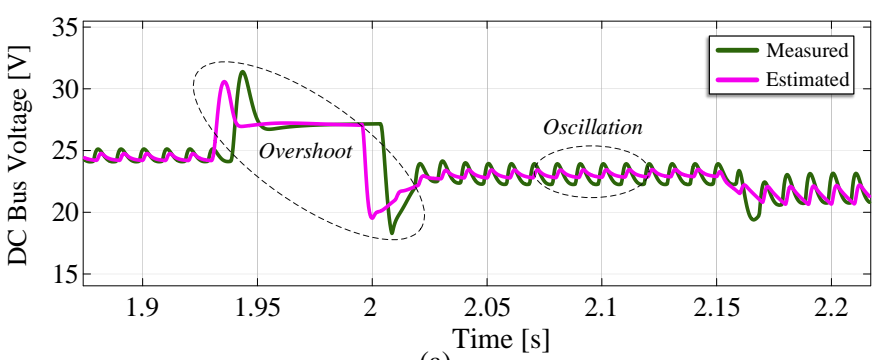

(a)

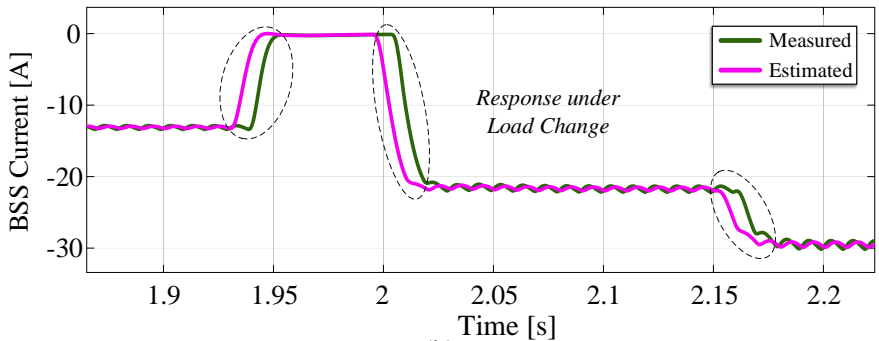

(b)

Fig. 14. Comparison of measured and estimated (a) DC bus voltages and (b) BSS currents under load change related to another time interval.

Once no-load exists in the system and also input values such as temperature, irradiance, and wind speed are variable and reasonable levels. Thus, that enables the SoC of the BSS is pretty satisfying and increasing rapidly, then the neural networks generate higher error values more than the other times. In other words, the error increases with the sudden charge of the batteries under the condition where the loads are not active and the inputs of DERs have satisfactory conditions. Thereby, we could infer that the proposed method can track the relevant signal with less error under load (output i.e., not input) changing conditions. Implemented ANNs are capable of controlling the changes rapidly. Furthermore, for the estimation of the WTS control (i.e., $\bar{I}_{W T}$ ), the percentage error value has a better rate than the others. When the loads are involved in the operation, it is expected that the error will increase with the change of the DC bus voltage, and then this situation can be observed to realize clearly. As can be expressed in Fig. 15, the error rates of these estimated values are shown in percent.

In this study, the best validation performance of $M S E$ was obtained as 8.156e-11 at 1000 epochs and correlation coefficient- $R$ (i.e., all regression values after training, validation, and test sets) as 1 for ANN2. As can be seen obviously in Figs. 4 and 5, four main controllers have critical duties in the system such as MPPT, WT, BSS, and Inverter control. Four different ANNs were created to manage these controllers. ANN1 and ANN2 are operated for MPPT, WT, and BSS control with their output predicted values. Similarly, ANN3 is used for BSS and inverter control, whereas ANN4 is for WT, BSS, and inverter control. On the other hand, the success rates of these ANNs are shown in Table IV. Best performance of MSEs and all regression values i.e., training, validation, and lastly test sets of $R$ are given for each ANN as well. Regarding the implementation phase, the dataset has been shared with having split up training, validation, and testing parts. We have embedded $800001 \times$ (Nb of inputs) matrix, representing dynamic data 800001-1 time steps of input elements and targeted $800001 \mathrm{x} 1$ matrix as output, representing dynamic output data 800001-1 time steps of 1 element.
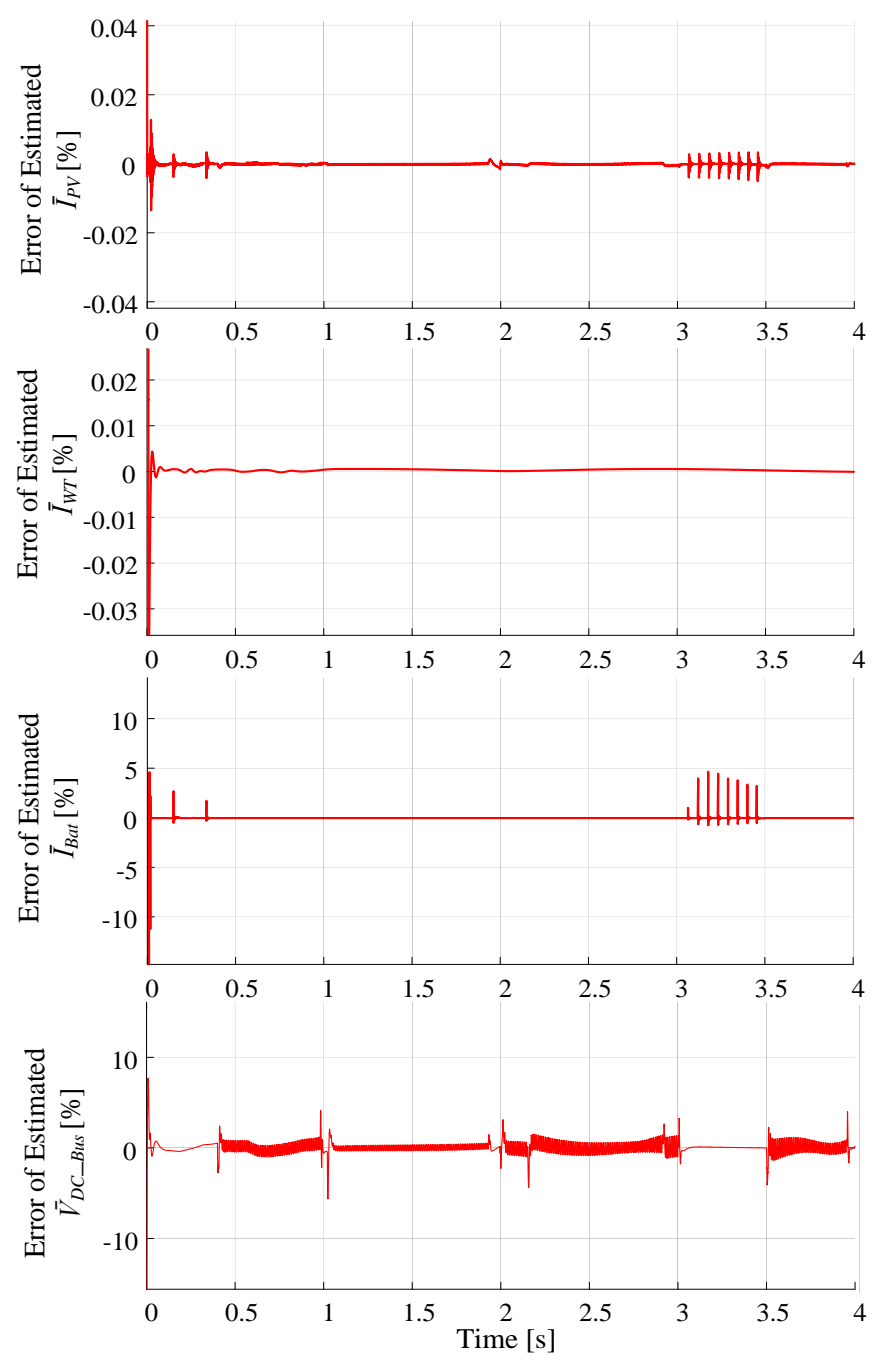

Fig. 15. The percentage error of estimated values.

Estimating the data with less oscillation which influences the system positively is profitable. On the other hand, it is evident that the amount of percent error is less than $10 \%$, that is, a high accuracy estimator at every moment of the simulation. As mentioned before, the load power at the moment when two loads are activated at the same time is also depicted in Fig. 16. The correlation between real and estimated controller is worth mentioning because the load power is not supposed to deviate from its conventional route scarcely like PI. The proposed control methodology makes the DC microgrid reliable by reducing the number of sensors and reducing the vulnerability to communication disturbance, which also decreases the cost of ownership of the sensors in the system. Besides, the sensors are eliminated as a result of performing with multi-layer feedforward ANNs which have a simple structure to be able to exploit the system with fast responses.

On the other hand, even trained networks by some sort of the signals that are received with the help of cascaded-PI cannot capture all the dynamics; however, the error rate of PI-trained neural networks is reasonably low in the system. In the training phase, the output of each network is fed by the main controller 
i.e., cascaded-PI. Supposing that the training process comprises a more suitable data set to be produced with the help of a better controller, the ANN is obvious that it can reach better results for the next exploitation phase.

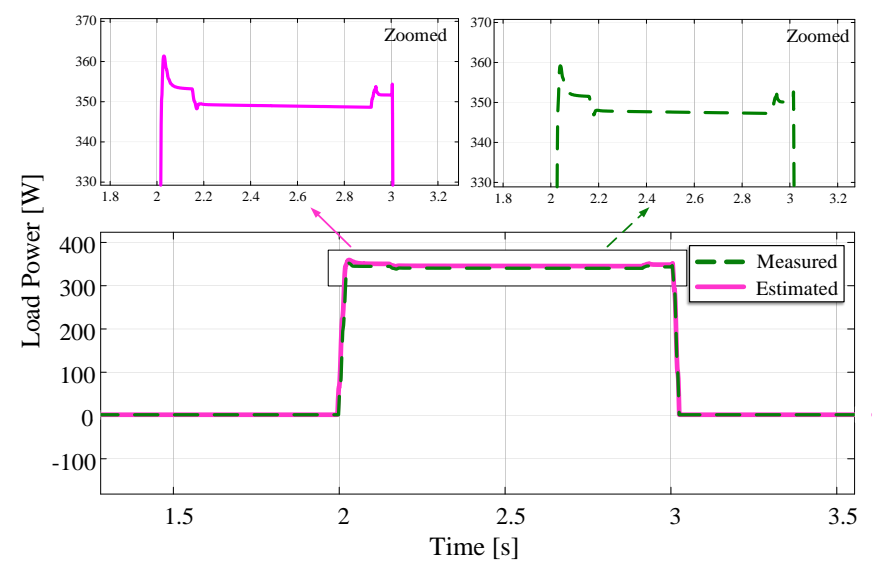

Fig. 16. Load power characteristic among the time interval of Load III and IV for cascaded-PI and ANN-based controller.

\section{CONCLUSION AND FUTURE WORK}

In this paper, without reducing the efficiency of the control application, an AI-based sensorless control has been highlighted and applied for the DC microgrid structure with the help of a nonlinear input-output neural network. This type of ANN is easy to apply and has proper estimating results with less complexity. Cascaded-PI-based current and voltage controllers have been performed to achieve the data essential for the offline training. To prove the effectiveness of the proposed control system, offline and online time-domain simulations have been implemented successfully under various operation conditions.

Reducing the number of sensors with that proposed method enables to eliminate the effect of communication delay which is caused by the sensors. The findings of this study support that the proposed controller has outperformed the conventional controller when compared to satisfying the loads with a rapid response, fewer oscillations, and larger reliability tolerance. The strong point of our work lies in envisaging four sensors data among all seven critical sensors data in the control of power electronic converters. Eliminating the number of sensors in the control layer has boosted the system's reliability as they do not require to be observed anymore. Our approach could be applied to DC microgrids.

With regard to, one of our future works; a comparison of another ANN output and its performance can be applied which is trained by different controllers such as sliding mode or model predictive controller instead of cascaded-PI. Secondarily, for the exploitation of more complex systems, a controller design to be based on a deep learning model by increasing the number of hidden layers in addition to the used type of ANNs for a more up-to-date network structure is within our scope.
APPENDIX

TABLE I

PARAMETERS OF ENERGY CONVERSION SYSTEM COMPONENTS

\begin{tabular}{|c|c|}
\hline PV ARRAY & \\
\hline Rated Maximum Power-Pm (kW) & 1 \\
\hline Maximum Power Current-Imp (A) & 32.68 \\
\hline Maximum Power Voltage-Vmp (V) & 30.6 \\
\hline Short Circuit Current-Isc (A) & 34.83 \\
\hline Open Circuit Voltage-Voc (V) & 36.3 \\
\hline Module Efficiency- $\eta(\%)$ & 15.40 \\
\hline \multicolumn{2}{|l|}{ WIND TURBINE } \\
\hline Turbine Type & Vertical Axis \\
\hline Rotor Diameter (m) & 1.17 \\
\hline Startup Wind Speed (m/s) & 3.58 \\
\hline Survival Wind Speed (m/s) & 49.2 \\
\hline Output Voltage (V) & 24 \\
\hline Rated Power (W) & 400 \\
\hline \multicolumn{2}{|l|}{ BATTERY STORAGE SYSTEM } \\
\hline Battery Type & Lead-Acid \\
\hline Nominal Voltage (V) & 12 \\
\hline Nominal Capacity (Ah) & 200 \\
\hline Internal Resistance (m $\Omega)$ & 3.4 \\
\hline Cut-off Voltage (V) & 9 \\
\hline Fully Charge Voltage (V) & 13.6 \\
\hline \multicolumn{2}{|l|}{ AC LOADS } \\
\hline Load I (0.40s - 0.98s \& 3.5s - 3.95s) & $440 \mathrm{~W}$ \\
\hline Load II $(1.02 \mathrm{~s}-1.93 \mathrm{~s})$ & $260 \mathrm{~W}$ \\
\hline Load III (1.99s - 3.00s) & $350 \mathrm{~W}$ \\
\hline Load IV (2.15s - 2.91s) & $160 \mathrm{~W}$ \\
\hline
\end{tabular}

TABLE II

FEATURES OF USED ANNS UNDER SYSTEM

\begin{tabular}{ccccc}
\hline \hline \multirow{2}{*}{ USED } & \multicolumn{4}{c}{ FEATURES } \\
\cline { 2 - 5 } ANN & $\begin{array}{c}\text { NB OF } \\
\text { INPUT }\end{array}$ & $\begin{array}{c}\text { NB OF } \\
\text { OUTPUT }\end{array}$ & $\begin{array}{c}\text { NB OF HIDDEN } \\
\text { NEURONS }\end{array}$ & $\begin{array}{c}\text { NB OF } \\
\text { DELAYS }\end{array}$ \\
\hline ANN1 & 3 & 1 & 10 & 5 \\
ANN2 & 3 & 1 & 10 & 2 \\
ANN3 & 5 & 1 & 10 & 2 \\
ANN4 & 3 & 1 & 10 & 6 \\
\hline \hline
\end{tabular}

TABLE III

INPUTS AND OUTPUTS OF ANNS' ELEMENTS

\begin{tabular}{cccc}
\hline \hline USED & \multicolumn{2}{c}{ ANN-ELEMENTS } & \\
\cline { 2 - 4 } SPACE & INPUT & OUTPUT & $\begin{array}{c}\text { REDUCED NB } \\
\text { OF SENSORS }\end{array}$ \\
\hline ANN1 & $G, T, V_{P V}$ & $\bar{I}_{P V}$ & 1 \\
ANN2 & $T_{M}, W_{S}, V_{W T}$ & $\bar{I}_{W T}$ & 1 \\
ANN3 & $\bar{I}_{P V}, \bar{I}_{W T}, I_{B a t(i n n)}, V_{B a t}, d$ & $\bar{I}_{B a t}$ & 3 \\
ANN4 & $\bar{I}_{B a t}, V_{B a t}, d$ & $\bar{V}_{D C \_B u s}$ & 2 \\
\hline \hline
\end{tabular}

TABLE IV

SUCCESS RATES OF ANNS ON RELEVANT CONTROLLER

\begin{tabular}{|c|c|c|c|}
\hline \multirow[b]{2}{*}{$\begin{array}{l}\text { USED } \\
\text { ANN }\end{array}$} & \multicolumn{3}{|c|}{ FEATURES } \\
\hline & $\begin{array}{c}\text { RELEVANT } \\
\text { CONTROLLER }\end{array}$ & $\begin{array}{c}\text { BEST } \\
\text { PERFORMANCE OF } \\
M S E\end{array}$ & $\begin{array}{c}R \\
(\text { TRA+VAL+TEST) }\end{array}$ \\
\hline ANN1 & $\begin{array}{l}\text { MPPT and BSS } \\
\text { Control }\end{array}$ & $1.894 \mathrm{e}-7$ & 0.99983 \\
\hline ANN2 & $\begin{array}{l}\text { WT and BSS } \\
\text { Control }\end{array}$ & $8.156 \mathrm{e}-11$ & 1 \\
\hline ANN3 & $\begin{array}{c}\text { BSS and } \\
\text { Inverter Control }\end{array}$ & $11.866 \mathrm{e}-5$ & 0.98966 \\
\hline ANN4 & $\begin{array}{l}\text { WT, BSS, and } \\
\text { Inverter Control }\end{array}$ & $8.223 \mathrm{e}-4$ & 0.98979 \\
\hline
\end{tabular}

\section{ACKNOWLEDGMENT}

The authors would like to thank Aalborg University, 
Marmara University-BAPKO (Bilimsel Araştırma Projeleri Birimi) with the project of which number is FEN-C-DRP150218-0063, and lastly the YUDAB scholarship commission by The Council of Higher Education (YÖK) for their supports.

\section{REFERENCES}

[1] D.T. Ton and W.P. Wang, "A more resilient grid: The U.S. department of energy joins with stakeholders in an R\&D plan," IEEE Power Energy Mag., vol.13, no. 3, pp. 26-34, Apr. 2015.

[2] N. Karami, N. Moubayed, and R. Outbib, "Energy management for a PEMFC-PV hybrid system," Energy Convers. Manag., vol. 82, pp. 154168, Jun. 2014.

[3] A. C. Luna, L. Meng, N. L. Diaz, M. Graells, J. C. Vasquez, and J. M. Guerrero, "Online Energy Management Systems for Microgrids: Experimental Validation and Assessment Framework," IEEE Trans. Power Electron., vol. 33, no. 3, pp. 2201-2215, March 2018.

[4] Y. Han, H. Li, P. Shen, E. A. A. Coelho, and J. M. Guerrero, "Review of active and reactive power sharing strategies in hierarchical controlled microgrids," IEEE Trans. Power Electron., vol. 32, no. 3, pp. 2427-2451, March 2017.

[5] S. Ullah, A. M. A. Haidar, and H. Zen, "Assessment of technical and financial benefits of AC and DC microgrids based on solar photovoltaic," Electr. Eng., vol. 143, pp. 1-14, Feb. 2020.

[6] T. Dragicevic, J. M. Guerrero, J. C. Vasquez, and D. Skrlec, "Supervisory control of adaptive-droop regulated DC microgrid with battery," IEEE Trans. Power Electron., vol. 29, no. 2, pp. 695-706, Feb. 2014.

[7] S. Zuo, T. Altun, F. L. Lewis and A. Davoudi, "Distributed Resilient Secondary Control of DC Microgrids Against Unbounded Attacks," in IEEE Trans. Smart Grid, vol. 11, no. 5, pp. 3850-3859, Sept. 2020.

[8] J. Hu, Y. Xu, K. W. Cheng, and J. M. Guerrero, "A model predictive control strategy of PV-Battery microgrid under variable power generations and load conditions," Appl. Energy, vol. 221, pp. 195-203, Jul. 2018.

[9] W. Jing, C. Hung Lai, S. H. W. Wong, and M. L. D. Wong, "Batterysupercapacitor hybrid energy storage system in standalone DC microgrids: areview," IET Renew. Power Gener., vol. 11, no. 4, pp. 461469, May 2017.

[10] C. Gouveia, J. Moreira, C. L. Moreira, and J. A. Peças Lopes, "Coordinating storage and demand response for microgrid emergency operation," IEEE Trans. Smart Grid, vol. 4, no. 4, pp. 1898-1908, Dec. 2013.

[11] V. K. Singh, R. N. Tripathi, and T. Hanamoto, "HIL co-simulation of finite set-model predictive control using FPGA for a three-phase VSI system," Energies, vol. 11, no. 4, p. 909, Apr. 2018.

[12] Q. Shafiee, J. M. Guerrero, and J. C. Vasquez, "Distributed secondary control for islanded microgrids-A novel approach," IEEE Trans. Power Electron., vol. 29, no. 2, pp. 1018-1031, Feb. 2014.

[13] A. Mohammed, S. S. Refaat, S. Bayhan, and H. Abu-Rub, "AC Microgrid Control and Management Strategies: Evaluation and Review," IEEE Power Electron. Mag., vol. 6, no. 2, pp. 18-31, Jun. 2019.

[14] S. K. Jha, J. Bilalovic, A. Jha, N. Patel, and H. Zhang, "Renewable energy: Present research and future scope of Artificial Intelligence," Renew.Sust. Energ. Rev., vol. 77, pp. 297-317, Sep. 2017.

[15] S. Zhao, F. Blaabjerg, and H. Wang, "An Overview of Artificial Intelligence Applications for Power Electronics," IEEE Trans. Power Electron., vol. 36, no. 4, pp. 4633-4658, Apr. 2021.

[16] A. Khandelwal and J. Kumar, "Applications of AI for Power Electronics and Drives Systems: A Review," 2019 Innovations in Power and Advanced Computing Technologies (i-PACT), Vellore, India, 2019, pp. 16.

[17] S. E. De Leon-Aldaco, H. Calleja, and J. A. Alquicira, "Metaheuristic optimization methods applied to power converters: A review," IEEE Trans. Power Electron., vol. 30, no. 12, pp. 6791-6803, Dec. 2015.

[18] L. Duchesne, E. Karangelos, and L. Wehenkel, "Recent developments in machine learning for energy systems reliability management," Proc. IEEE, Early Access, pp. 1-21, May 2020.

[19] R. C. G. Joao Pinto and Burak Ozpineci, "Tutorial: Artificial intelligence applications to power electronics," in IEEE Energy Convers. Congr. Expo., 2019, pp. 1-139.

[20] A. Nabi Akpolat, Y. Aysel Baysal, Y. Yang, and F. Blaabjerg, "Optimal PV Generation Using Symbiotic Organisms Search Optimization Algorithm-Based MPPT," IECON 2020 The 46th Annual Conference of the IEEE Industrial Electronics Society, Singapore, Singapore, 2020, pp.
2850-2855.

[21] Q. Xu, N. Vafamand, L. Chen, T. Dragičević, L. Xie, and F. Blaabjerg, "Review on Advanced Control Technologies for Bidirectional DC/DC Converters in DC Microgrids," IEEE Trans. Emerg. and Sel. Topics Power Electron., Mar. 2020.

[22] D. Pérez-Estévez and J. Doval-Gandoy, "AC Voltage Sensorless Method with Bumpless Start for Current-Controlled Converters Connected to Microgrids," 2018 IEEE Energy Conversion Congress and Exposition (ECCE), Portland, OR, 2018, pp. 194-201.

[23] B. Karanayil and M. F. Rahman, "Artificial neural network applications in power electronics and electric drives," in Power Electronics Handbook, 4th ed. Amsterdam, The Netherlands: Elsevier, 2018, pp. 1245-1260.

[24] A. Egea-Àlvarez, M. Aragüés-Peñalba, O. Gomis-Bellmunt, J. RullDuran, and A. Sudrià-Andreu, "Sensorless control of a power converter for a cluster of small wind turbines," IET Renew. Power Gener., vol. 10, no. 5, pp. 721-728, Apr. 2016.

[25] T. Syskakis and M. Ordonez, "MPPT for Small Wind Turbines: ZeroOscillation Sensorless Strategy," 2019 IEEE 10th International Symposium on Power Electronics for Distributed Generation Systems (PEDG), Xi'an, China, 2019, pp. 1060-1065.

[26] K. Renu, N. K. Kumari, and D. S. G. Krishna, "Sensorless Control of Permanent Magnet Synchronous Motor with Flux Weakening Operation for Washing Machine Application," 2018 IEEE International Conference on Power Electronics, Drives and Energy Systems (PEDES), Chennai, India, 2018.

[27] P. Liu, Y. Wang, J. Li, and D. Liu, "Advanced sensorless power control strategy of renewable microgrids for reliability enhancement," Appl. Energy, vol. 255, 113850, Dec. 2019.

[28] N. Chettibi and A. Mellit, "Intelligent control strategy for a grid connected PV/SOFC/BESS energy generation system," Energy, vol. 147, pp. 239262, Mar. 2018.

[29] N. Pimkumwong and M. Wang, "An Online Artificial Neural Network Speed Estimator for Sensorless Speed Control of Separately Excited DC Motor," 2018 15th International Conference on Electrical Engineering/Electronics, Computer, Telecommunications and Information Technology, Chiang Rai, Thailand, 2018, pp. 37-40.

[30] H. Teiar, H. Chaoui, and P. Sicard, "Almost parameter-free sensorless control of PMSM," IECON 2015 - 41st Annual Conference of the IEEE Industrial Electronics Society, Yokohama, 2015.

[31] C. Chatri and M. Ouassaid, "Sensorless Control of the PMSG in WECS Using Artificial Neural Network and Sliding Mode Observer," 2018 International Symposium on Advanced Electrical and Communication Technologies (ISAECT), Rabat, Morocco, 2018.

[32] M. N. Akhter, S. Mekhilef, H. Mokhlis, and N. Mohamed Shah, "Review on forecasting of photovoltaic power generation based on machine learning and metaheuristic techniques," IET Renew. Power Gener., vol. 13, no. 7, pp. 1009-1023, May 2019.

[33] A. Rosato, M. Panella, R. Araneo and A. Andreotti, "A Neural Network Based Prediction System of Distributed Generation for the Management of Microgrids," IEEE Trans. Ind. Appl., vol. 55, no. 6, pp. 7092-7102, Nov.-Dec. 2019.

[34] A. Haque, "AC-DC converters (rectifiers)," in Electric Renewable Energy Systems, 1st ed., USA: Academic Press, 2016, pp. 313-336.

[35] S. Samara and E. Natsheh, "Intelligent Real-Time Photovoltaic Panel Monitoring System Using Artificial Neural Networks," IEEE Access, vol. 7, pp. 50287-50299, Apr. 2019.

[36] M. R. Habibi, H. R. Baghaee, T. Dragicevic, and F. Blaabjerg, "Detection of False Data Injection Cyber-Attacks in DC Microgrids based on Recurrent Neural Networks," IEEE Trans. Emerg. and Sel. Topics Power Electron. Jan. 2020.

[37] I. S. Mohamed, S. Rovetta, T. D. Do, T. Dragicević, and A. A. Z. Diab, "A Neural-Network-Based Model Predictive Control of Three-Phase Inverter With an Output LC Filter," IEEE Access, vol. 7, pp. 124737 124749, Aug. 2019.

[38] N. Saxena, I. Hussain, B. Singh and A. L. Vyas, "Implementation of a Grid-Integrated PV-Battery System for Residential and Electrical Vehicle Applications," IEEE Trans. Ind. Electron., vol. 65, no. 8, pp. 6592-6601, Aug. 2018.

[39] P. S. Kumar, R. P. S. Chandrasena, V. Ramu, G. N. Srinivas and K. V. S. M. Babu, "Energy Management System for Small Scale Hybrid Wind Solar Battery Based Microgrid," IEEE Access, vol. 8, pp. 8336-8345, 2020.

[40] L. Che and M. Shahidehpour, "DC Microgrids: Economic Operation and Enhancement of Resilience by Hierarchical Control," IEEE Trans. Smart Grid, vol. 5, no. 5, pp. 2517-2526, Sep. 2014. 


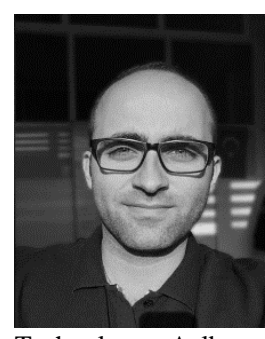

Alper Nabi Akpolat (S'19) received the B.Sc. degree in Electrical-Electronics Engineering and the M.Sc. degree in Mechatronics Engineering from Firat University, Elazig, Turkey, in 2012 and 2015, respectively. He is currently working toward the Ph.D. degree in Electrical-Electronics Engineering and also serving as a Research Assistant, from Faculty of Technology, at Marmara University.

From March 2019, he was a Guest Ph.D. student during one year with Department of Energy Technology, Aalborg University, Denmark. His research interests include renewable energy systems, DC microgrids, applied artificial intelligence in power electronics and power systems, and control of distributed generation systems.

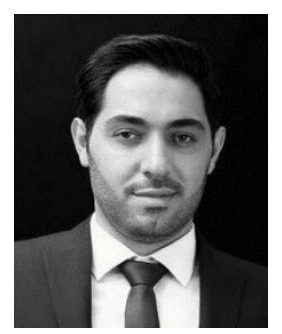

Mohammad Reza Habibi (S'19) was born in Tehran, Iran. He is currently working toward the $\mathrm{Ph} . \mathrm{D}$. degree with the Department of Energy Technology, Aalborg University, Denmark. He is also a Visiting Research Scholar with the Department of Electrical Power Engineering and Mechatronics, Tallinn University of Technology, Tallinn, Estonia.

His current research interests include intelligent energy systems, application of artificial intelligence in power electronics and power systems, advanced control of power converters, modeling and control of energy storage systems, modeling and secure control of DC distribution systems and microgrids, and cyber-physical systems.

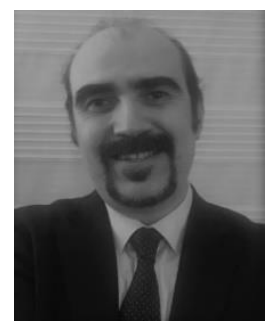

Erkan Dursun (S'05-M'13) received the B.Sc. degree (2001), the M.Sc. degree (2006), and Ph.D. degree (2013) in Electric Education, Faculty of Technical Education from Marmara University in Istanbul, Turkey. From 2010 to 2012, he was visiting fellow UNIDO-ICHET (United Nations Industrial Development Organization - International Centre for Hydrogen Energy Technologies).

From 2012 to 2013, he was a researcher with the Joint Research Center, European Commission, Italy. His research interest includes distributed generation, hybrid power systems, and smart grid. Dr. Dursun has become a member of IEEE for ten years, and also his papers have received more than 520 in SCI database of Thomson Reuters.

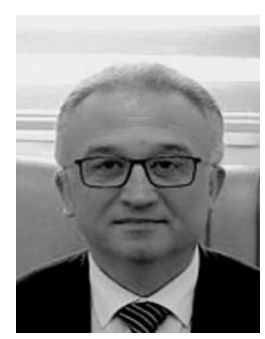

Ahmet Emin Kuzucuoğlu (M'99) received his B.Sc. degree from Electronics and Telecommunication Engineering Department, Istanbul Technical University, Turkey, in 1985 and he received his M.Sc. and Ph.D. degrees from Marmara University, in 1994 and 2000, respectively. He is an Associate Professor with the Department of Electrical-Electronics Engineering.

Since 2017, He has also been serving as a Vice Dean of the Faculty of Technology at Marmara University, Istanbul, Turkey. Dr. Kuzucuoğlu is now an Editor-in-Chief for journal of PORTA. His research interests include industrial automation, robotics, artificial intelligence, control theory and applications.

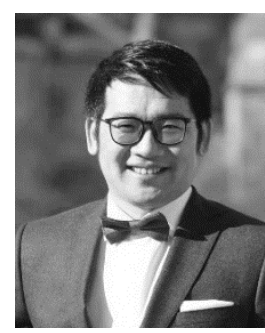

Yongheng Yang (SM'17) received the B.Eng. degree from Northwestern Polytechnical University, China, in 2009 and the Ph.D. degree from Aalborg University, Denmark, in 2014. He was a postgraduate student with Southeast University, China, from 2009 to 2011. In 2013, he spent three months as a Visiting Scholar at Texas A\&M University, USA. Currently, he is an Associate Professor with the Department of Energy Technology, Aalborg University, where he is also the Vice Program Leader for the research program on photovoltaic systems.
Dr. Yang is the Chair of the IEEE Denmark Section. He is now an Associate Editor for several prestigious IEEE Transactions/Journals. He is a Deputy Editor of the IET Renewable Power Generation for Solar Photovoltaic Systems. He was the recipient of the 2018 IET Renewable Power Generation Premium Award and was an Outstanding Reviewer for the IEEE TRANSACTIONS ON POWER ELECTRONICS in 2018. His current research includes the gridintegration of photovoltaic systems and multi-energy vectors with an emphasis on the power converter design, control, and reliability.

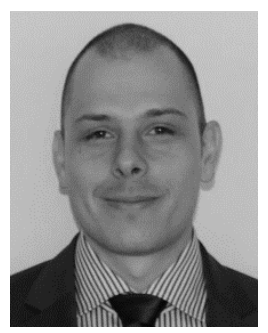

Tomislav Dragičević (S'09-M'13-SM'17) received the M.Sc. and the industrial Ph.D. degrees in Electrical Engineering from the Faculty of Electrical Engineering, Zagreb, Croatia, in 2009 and 2013, respectively. From 2013 until 2016, he has been a Postdoctoral research associate at Aalborg University, Denmark. From March 2016 until 2020, he has been an Associate Professor at Aalborg University, Denmark. From April 2020, he is a Professor at the Technical University of Denmark. He made a guest professor stay at Nottingham University, UK, during spring/summer of 2018.

His principal field of interest is the design and control of DC distributions systems and microgrids and the application of advanced modeling and control concepts to power electronic systems. He has authored and co-authored more than 200 technical publications (more than 100 of them are published in international journals, mostly in IEEE) in his domain of interest, 8 book chapters, and a book in the field. He serves as Associate Editor in the IEEE TRANSACTIONS ON INDUSTRIAL ELECTRONICS, in IEEE TRANSACTIONS ON POWER ELECTRONICS, in IEEE EMERGING AND SELECTEd TOPICS IN POWER Electronics and in IEEE Industrial Electronics Magazine. Prof. Dragičević is a recipient of the Končar prize for the best industrial Ph.D. thesis in Croatia, a Robert Mayer Energy Conservation award, and from 2019 he is an Alexander von Humboldt fellow.

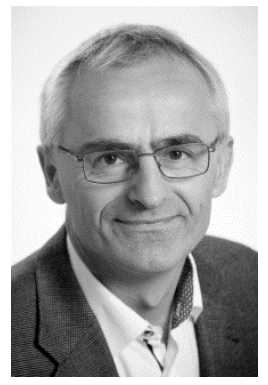

Frede Blaabjerg (S'86-M'88-SM'97-F'03) was with ABB-Scandia, Randers, Denmark, from 1987 to 1988. From 1988 to 1992 , he got the $\mathrm{PhD}$ degree in Electrical Engineering at Aalborg University in 1995. $\mathrm{He}$ became an Assistant Professor in 1992, an Associate Professor in 1996, and a Full Professor of power electronics and drives in 1998. From 2017 he became a Villum Investigator. He is honoris causa at University Politehnica Timisoara (UPT), Romania and Tallinn Technical University (TTU) in Estonia.

His current research interests include power electronics and its applications such as in wind turbines, PV systems, reliability, harmonics and adjustable speed drives. He has published more than 600 journal papers in the fields of power electronics and its applications. He is the co-author of four monographs and editor of ten books in power electronics and its applications.

He has received 32 IEEE Prize Paper Awards, the IEEE PELS Distinguished Service Award in 2009, the EPE-PEMC Council Award in 2010, the IEEE William E. Newell Power Electronics Award 2014, the Villum Kann Rasmussen Research Award 2014, the Global Energy Prize in 2019 and the 2020 IEEE Edison Medal. He was the Editor-in-Chief of the IEEE TRANSACTIONS ON POWER ElECTRONICS from 2006 to 2012. He has been Distinguished Lecturer for the IEEE Power Electronics Society from 2005 to 2007 and for the IEEE Industry Applications Society from 2010 to 2011 as well as 2017 to 2018. In 2019-2020 he serves a President of IEEE Power Electronics Society. He is Vice-President of the Danish Academy of Technical Sciences too. He is nominated in 2014-2019 by Thomson Reuters to be between the most 250 cited researchers in Engineering in the world. 